\title{
SOME ANATOMICAL PROBLEMS IN NAVAL WARFARE
}

\author{
BY \\ G. WEDDELL and H. D. DARCUS \\ From the Department of Human Anatomy, University of Oxford
}

(RECEIVED FOR PUBLICATION, JULY 23, 1946)

In general, our problems have been concerned with the determination of conditions of work which allow personnel to perform certain routine operations (such as the loading of a heavy gun) precisely, rapidly, and with the minimum of fatigue and discomfort. Having established these conditions by experiment, the results are then applied to the design of machines or weapons as far as mechanical requirements and considerations of limitation of space and weight permit. This procedure leads to a greater efficiency in operation and to a greater economy in manufacture than the usual method, in which the machine receives first consideration and the operator is left to fit himself to the machine as best he can. Owing to improvements in electrical, hydraulic and mechanical design, and to the increased working speed attainable, the weakest link in the operation of any machine is now ' the man behind it.' It is for this reason that so much more attention is being paid to the human factors in engineering design.

Our work for the Navy has included the design of hand and foot controls which may be used in the operation of guns and directors; the design of seats for directors; the design of air look-out sights and moving eyepiece range finders; the design of an emergency power unit using human energy, for the operation of hydraulic light-powered mountings; investigations into the alleviation of vertical thrust injuries due to underwater blast and to vibration in motor torpedo boats; the effects of clothing on the efficiency of operation; the effect of cordite on the efficiency of magazine personnel; and the determination and analysis of composite joint movements, such as those occurring in the spine. In this communication it is not possible to deal with all these aspects of our work. However, two examples have been selected which illustrate the application of the principles we have employed and the results we have obtained; they are the design of a seat capable of fitting all subjects with the minimum of adjustment, and the construction of a high-angle sight, pivoted so that the binoculars can be followed by the eyes with relative ease and without undue straining.

\section{Seats}

Seating is a problem which hitherto has received very little attention. This was especially the case in the Navy, for in this Service it is traditional to stand when on duty. However, mainly on account of the increasing menace from air attack in modern naval warfare, it has become imperative to be prepared for immediate offensive and defensive action at all times. This often necessitates watches being at ' action stations' for many hours. To perform such duties while standing incurs an unnecessary expenditure of energy, which leads to an early onset of fatigue with a consequent decrease of efficiency in operating precision apparatus. Thus the provision of adjustable seats designed to minimize discomfort and to allow efficient operation of machines becomes an important matter.

\section{Desiderata}

The chief requirements of an 'ideal' seat for use in naval operations are: (1) the accommodation of individuals of different body dimensions within the 90 per cent. (minimum acceptable) range; (2) the ability to attain the maximum degree of body stabilization; (3) the elimination of fatigue; and (4) freedom from breakdown.

1. Accommodation of personnel.-The seat must accommodate 90 per cent. of all naval personnel without the operator fouling surrounding structures, but at the same time it must occupy the least possible space. A simple single adjustment of seat height must be provided, so that persons of different stature can fit themselves accurately and rapidly to the seat. The adjustment of seat level must be related to the foot-rest, to allow for varying leg lengths, and also to the oculars of the sight, to allow for varying eye levels.

2. Body stabilization.-A method of body stabilization is essential in order to counteract the movements of the ship, gun, or director while observations are being made and operations carried out, 
thus making it possible to increase the accuracy of aim, and to prevent ' throw off.' Whatever method is adopted the arms must be left free to manipulate controls, and the mobility of the spine must not be limited. Stabilization by the use of a retaining mechanism is undesirable, for it is liable to restrict the movements of the arms and trunk, and also it unnecessarily increases the manipulations to be performed by the operator, who may have to take up his position in the dark; it adds to the complexity of the equipment, and the adjustment of the harness takes time. Furthermore, the feeling that the harness, even though it may be fitted with a quick-release

- catch, may hinder rapid escape, has an undesirable psychological effect on the ratings. Body stabilization should be effected by the operator himself with the minimum of muscular effort by counter-pressure between a foot-rest and a back-rest.

3. Elimination of fatigue.-To reduce fatigue to a minimum the seat must provide an efficient, comfortable support to the body over prolonged periods. In order to realize this ideal, the design of $(a)$ the seat cushion, $(b)$ the foot-rest, and (c) the back-rest must all be considered.

(a) The seat cushion must be wide enough to accommodate subjects of maximum dimensions wearing thick winter clothing, and must allow a certain amount of lateral movement. Its depth must be sufficient to afford light support to the thighs. The thighs must not press heavily against the front edge of the cushion, for this may lead to discomfort and possible interference with the blood supply of the leg. The cushion must not project so far forward that it interferes with the free movement of the legs. It is desirable that the part of the cushion supporting the ischial tuberosities should be flat and disposed horizontally. One of the advantages of this is that it permits the operator to change his position readily during periods of relaxation, thus resting different muscle groups in turn and allowing transference of pressure from one part of the buttock to another during prolonged watches. In practice this has been found to minimize discomfort and fatigue. The cushion should be resilient, but the resilience should only be in a vertical plane as any lateral or fore-and-aft sway will lead to instability. The resilience should be of such a degree that the body weight, taken on the buttocks, is distributed over as large an area as possible, with the proviso that the maximum pressure remains over the ischial tuberosities. This last consideration is, based on the observation that the skin in this area, unlike that surrounding it, is specially modified in blood supply to withstand prolonged pressure (Edwards and Duntley, 1939). (b) The foot-rest should be placed so that the foot is maintained at right angles to the leg for, when they are at rest in this position, both the anterior and posterior groups of leg muscles are relaxed, and when exerting pressure both groups are contracting equally so that no undue strain is thrown on either group. The relation of the foot-rest to the seat must also be determined accurately, so that when the seat height is adjusted to the ocular height the knee angle will be in a position for exerting maximum counter-pressure.

(c) The back-rest should be so placed that it affords comfortable support to the body, allowing free movement of the spine, and so that maximum counter-pressure between it and a suitably placed foot-rest can be obtained without 'throw off' in instances when pressure has to be developed suddenly while the operator is manipulating controls. The transverse curve of the back-rest must conform to the anatomical curvature of the lumbar region, and the dimensions of the back-rest should permit the accommodation of individuals of varying sizes.

4. Freedom from breakdown.-Apart from the anthropometric, anatomical, and physiological requirements outlined above, there are mechanical factors which must be taken into consideration. The individual components of the seat assembly must be capable of withstanding very severe usage, and must be weather-proof, water-proof, fire-proof, rot-proof, oil-proof, and termite-proof. The construction of the seat must combine maximum strength with minimum weight and size, and must provide for easy maintenance. Finally, the design must not interfere with rapid access to, or escape from, the seat.

\section{Dimensions and Desígn}

1. Anthropometric Data.-The calculations for dimensions of the seat are based on the American Fort Knox survey of body measurements of military personnel. We used this survey as a standard reference for anthropometric data, because it was available before any British survey was published, and because the method of presentation of the data is particularly suited for use in the problems with which we are concerned. Recently we have compared this survey with the body measurements of British tank personnel obtained by the Department of Biological Research of the War Office with the collaboration of Dr. G. M. Morant and Prof. A. Bradford Hill, and, from the point of view of our investigations, there is no' appreciable difference between selected groups of American and British subjects. On occasions when no relevant data were available, we obtained the required measurements ourselves from representative groups of individuals.

2. Body Stabilization.-For naval purposes, body stabilization is of prime importance; it was, therefore, given first consideration in the design of the 

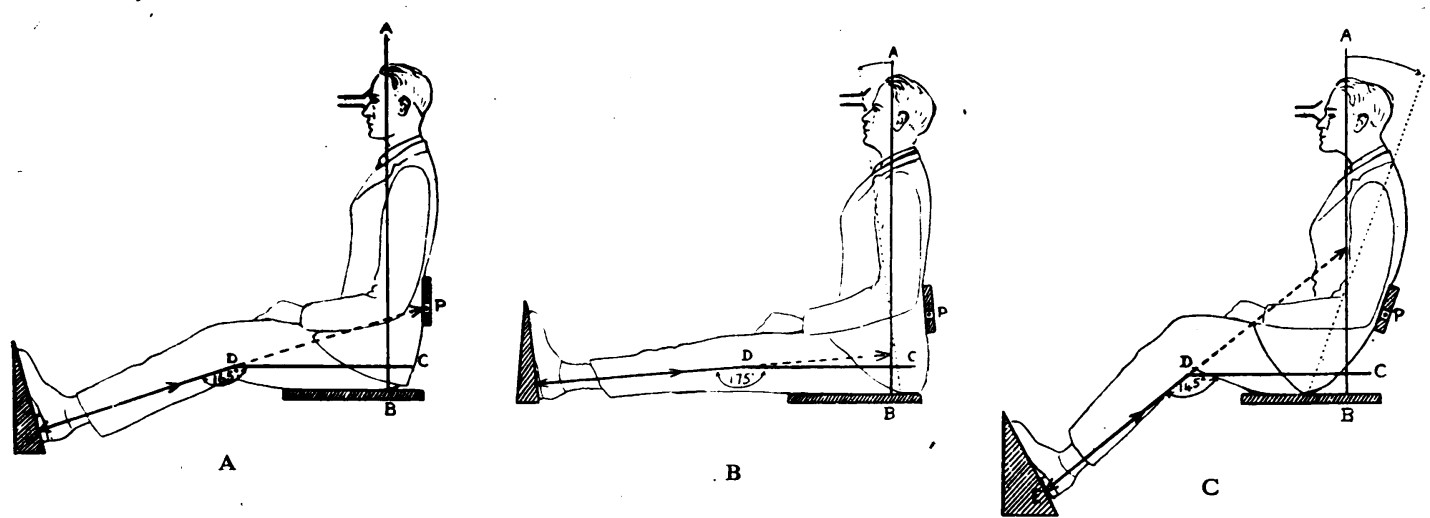

FIG. 1.-(a) The optimum position for body stabilization between foot-rest and back-rest. There is no eye displacement or tendency to 'throw off' when pressure is exerted. (b) The angle at the knee joint is too obtuse. The buttocks tend to get wedged between the seat and the back-rest. There is eye displacement and a tendency to "throw off' when pressure is exerted. (c) The angle at the knee joint is too acute. The body tends to rise in the seat. There is eye displacement and a tendency to 'throw off' when pressure is exerted.

seat. Complete body stabilization can be obtained most satisfactorily without the use of any retaining mechanism. It can be achieved by counter-pressure between the feet against a foot-rest, and the back against a back-rest. Obviously, the position of the legs and body in which the maximum counterpressure can be developed (provided it does not introduce any discomfort leading to fatigue) is the ideal one for stabilization. The more the position varies from the optimum, the greater the output of energy necessary to maintain equivalent pressures, since the muscles are working at a decreasing mechanical advantage. The optimum position of the foot-rest and back-rest in relation to the seat to obtain maximum counterpressure was calculated from the results of direct experiment by Dr. Hugh-Jones on thrusts exertable on tank brake- and clutchpedals. Previous work on naval problems had indicated that the thrust of the legs against a footrest rises with increasing knee angles. The work of Hugh-Jones went further and showed that, when the angle of the thigh to the body remains constant, the maximum thrust rises as the knee angle increases up to a welldefined 'limiting angle' of $165^{\circ}$ to $170^{\circ}$, above which, as the knee straightens and then extends, the thrust obtainable falls precipitously. The explanation of this seems to be that, with a man of average bodily dimensions sitting in such a position, the line of thrust passes through the pivotal axis of the back-rest when the latter is in the optimum position. If the knee angle is smaller, the thrust is directed above the back-rest, so that when exerting pressure with the feet there is a tendency (which has to be restrained) for the upper part of the body to be pushed back. Conversely, if the knees are held at an angle greater than $165^{\circ}$, the thrust tends to incline the body forward. Both these movements result in instability and loss of counter-pressure (fig. 1 $a-c)$. Recently, it has been shown that in cadavers the increase of tension resulting from increasing the knee angle may be due to the patella being drawn

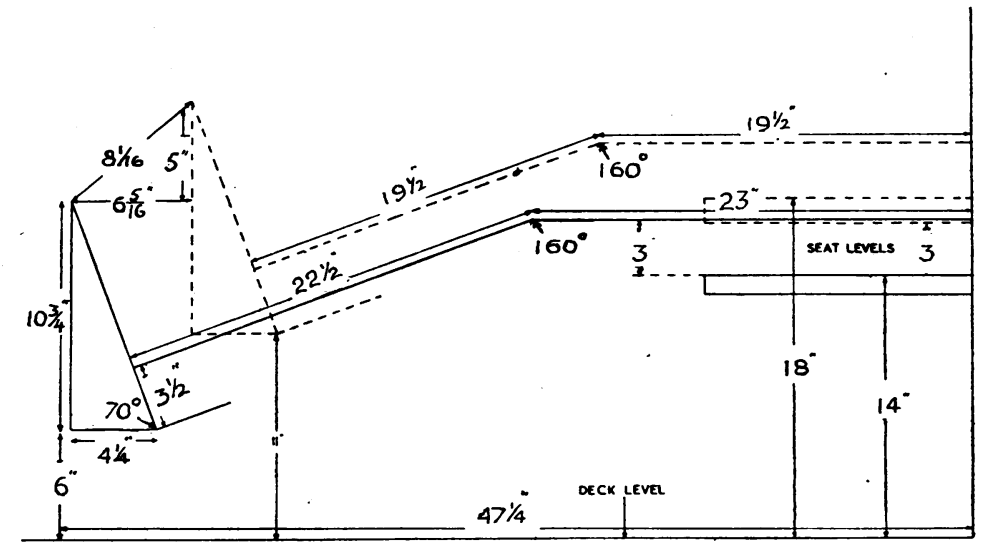

FIG. 2.-This gives the dimensions and range of adjustments in inches for a seat in which stabilization is effected between back- and foot-rests. 
upwards over the femoral condyles and being displaced farther from the centre of the knee joint as the knee is extended, thus, allowing the quadriceps muscle to work at a greater mechanical advantage. (Haxton, 1945).

From the observations outlined above, it will be obvious that it is necessary to have a seat with an adjustable foot-rest so that in different individuals a knee angle of $160^{\circ}$ can be obtained. In practice, an angle of $160^{\circ}$ is aimed at, for when counter-pressure is developed the knee angle tends to increase, due to the 'give' in the seat pressure. In such a position the stability achieved is so great that a subject can easily remain in his seat when it is rolled over from side to side, even when less than the maximum counter-pressure is being exerted. In naval operations the maximum extrinsic force tending to displace an operator from his seat is estimated at about $200 \mathrm{lb}$., whereas the mean thrust possible with each leg is over $500 \mathrm{lb}$. (fig. 2).

3. The seat cushion.-The next important consideration is the design of the seat cushion.' Reference to anthropometric data shows that the cushion should be at least 15 inches wide, and 18 inches deep. It is found that in practice a flat cushion is not completely satisfactory, for when the subject is sitting in the optimum position (that is, with upper surfaces of the thighs horizontal and the knee at an angle of $160^{\circ}$ ), the distal part of the underside of the thigh is not supported by the cushion, because it slopes upwards at an angle of about $10^{\circ}$ to the horizontal in the average subject. To compensate for this, and at the same time to retain the advantage of a flat seat, the front 8 inches should be sloped at an angle of about $10^{\circ}$ to the horizontal, and the back 10 inches disposed horizontally. It is essential that the front edge of the cushion should be softly sprung to prevent undue pressure on the underside of the thigh, and also to allow for any variation in the slope of the underside of the thigh in different individuals.

To obtain the correct resilience without fore-andaft sway, we have found that the most suitable type of springing consists of flexible steel strips fixed transversely. Such springs have the added advantage that they can be made to give any required degree of resilience. Moreover, with this method of springing, the resilience does not vary even with prolonged use. Thus it enables an individual to adjust his seat to a given height, so that he is always in the correct position to operate his sight, gun, or other instrument. The selection of a suitable seatcovering proved somewhat difficult, but success has been achieved by the use of transversely fluted first- quality hide, overlying DDT-impregnated horsehair and stitched to treated hessian. Such a covering will stand arctic cold as well as tropical heat, and is comfortable to sit on when the only clothes worn are shorts and when sweat is abundant. In the past, first-quality hide was a staff requirement for officers' furniture only, whereas, of course, it should be fitted where it is subjected to the most severe usage.

The optimum height of the back-rest corresponds to the level of the maximum concavity of the lumbar curvature. The height of this level above the ischial tuberosities was determined in 50 male subjects, and in individuals within the $\mathbf{9 0}$ per cent. range of sitting height this was found to vary between 8 and 12 inches. It was thought at first that a back-rest which was adjustable in height would be necessary in order to give efficient support to the backs of all individuals, but practical tests showed that a backrest 5 inches in vertical depth, with its centre 10 inches above the level of the compressed seatcushion, was satisfactory.

It was also necessary to determine the position of the back-rest in relation to the back of the seat. To do this, the position of the maximum concavity of the lumbar curvature in relation to the most backwardly projecting part of the buttocks was measured in 50 persons sitting erect. It - was found, on the average, that the lumbar spine at this level is half an

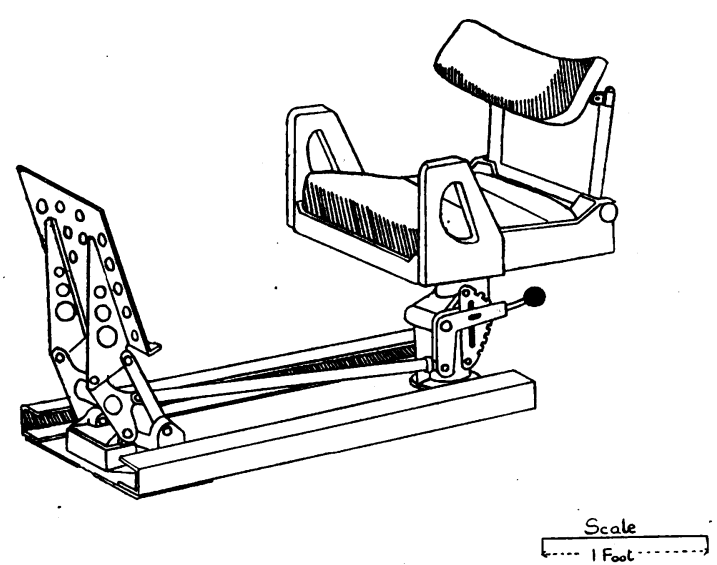

FIG. 3.-A form of seat for use by the Royal Navy based on the principles outlined in the text.

inch behind the buttocks, and thus the back-rest should be placed half an inch behind the back of the seat. Practical tests on a further large series of individuals showed that such a position was satisfactory. 
For efficient as well as comfortable support, the curve of the back-rest should correspond as accurately as possible to the natural curvature of the lumbar region in the horizontal plane. The average curvature in this plane was, therefore, determined in 25 subjects. Each individual was seated erect on a chair, and the curvature was measured 10 inches above the level of the seat, with and without the subject wearing winter clothing. The curves were recorded by means of a length of lead piping which was firmly moulded round the loins. The mean curve was only estimated for 4 inches on either side of the mid-line, and was found to be the arc of a circle of $7 \frac{5}{18}$ inches radius, whatever the clothing worn. Beyond this distance, individual curves varied so greatly that it was impossible to estimate a practical mean curve, although their radii never exceeded 71 inches. It was, therefore, decided to construct a back-rest having a radius of $7 \frac{5}{16}$ inches and a width of 15 inches. A 'mock-up' constructed from these data fitted all the subjects with a fair degree of accuracy, and, when sprung with steel strips fixed transversely and suitably covered with hide and horsehair, proved entirely satisfactory in all cases.

The position of the pivot of the back-rest is of importance if the latter is to follow easily the changing contour of the back when leaning forwards or backwards. It should, in all cases, be below the centre of the rest, because the force exerted against the back-rest by the counter-pressure of the feet is considerably greater than that derived from the upper part of the trunk.

5. The foot-rest.-The position of the foot-rest in relation to the seat was determined by considering the optimum position for body stabilization. The foot-rest must be long enough to support the largest booted foot, and wide enough to accommodate the feet in the most comfortable and efficient position for exerting pressure. To fulfil these requirements, it should be 14 inches long and 15 inches wide. A heel-rest should be provided at right angles to the foot-rest and this should be at least 3 inches deep. In order to accommodate a 90 per cent. range of subjects in the optimum position for body stabilization, the foot-rest must be adjustable. Fortunately, there is a good correlation between the leg-length and sitting-height, so that a link mechanism can be used which allows simultaneous adjustment of the seat and the foot-rest by moving a single lever.

6. The lateral thigh supports.-It was found that by fitting lateral thigh supports to the sides of the (seat in the front only) the comfort of the operator in the relaxed position was increased considerably. These prevent too great a degree of passive lateral rotation of the thighs, and so obviate strain on the adductor and medial rotator muscles, which must otherwise remain in a state of tonic contraction. These supports can be so placed that controls attached to them are in the correct position for precise manipulation by the hands. They can also be used as an aid to stabilization to some extent, if the thighs are forced against them. Fig. 3 illustrates a seat designed in accordance with the principles outlined above for use by the Royal Navy.

\section{High-Angle Optical Sights}

The increasing incidence of air attack on ships at sea during the war made the construction of highangle ocular sights imperative. Although 'Radar' has revolutionized plane-spotting, ocular sights still have an important rôle to play. Until rècently ocular sights for naval use have only been designed for low-angle observations, and, although satisfactory for this purpose, they are virtually impossible to use at high angles of elevation. The human. mechanics concerned in the design had, therefore, to be determined before a satisfactory sight could be constructed for high-angle observations.

\section{Desiderata}

From the anatomical point of view, there are two factors which must be considered if binocular sights are to be used to the best advantage.

1. The position of the operator must be such that his eyes are related correctly to the binocular eyepieces, both in the vertical and horizontal plane. This necessitates the design of a seat which allows essential adjustment to be made with ease and rapidity.

2. The binocular movement must be such that it follows the natural track taken by the eyes during elevation.

\section{Dimensions and Design}

1. Practical tests showed that the vertical adjustment of the eyes to the binocular eyepieces is of extreme importance. For maximum efficiency, the optical axis of the eyes of the observer and of the binoculars must be coincident. A maladjustment of half an inch above or below the optimum level results in a serious decrease in the degree of elevation attainable by the observer. The sitting eye-height of the 90 per cent. range of subjects was found to vary between 30 and 34 inches. As it is not possible to alter the position of the binoculars for 
observers of varying stature, the seat must be adjustable through the required range.

In addition, for maximum efficiency, the position of the binocular eyepieces should correspond to the normal position of the eyes when the observer is sitting erect in a natural manner and looking directly forwards. It was found by experiment that the natural position of the eyes in 50 individuals within the 90 per cent. range varied from $4 \frac{1}{2}$ to 6 inches in front of the vertical plane through the back-rest, the average being $5 \frac{1}{2}$ inches. Subsequent trials showed that with the eyepieces in the average position the mean maximum elevation without strain was greater than in other positions, but, providing the position of the eyepieces did - not vary more than one inch on either side of the average, the decrease in the mean maximum elevation was insufficient to justify the incorporation of a special adjusting mechanism in the sight.

2. The method used to determine the natural track of the eyes from a position of maximum depression up to zenith was an extension of that previously adopted by the Admiralty Research Laboratory at

\section{TABLE}

\begin{tabular}{l|c|c|c|c}
\hline Sight & $\begin{array}{c}60 \text { de- } \\
\text { grees } \\
\text { eleva- } \\
\text { tion } \\
\text { without } \\
\text { strain }\end{array}$ & $\begin{array}{c}90 \text { de- } \\
\text { grees } \\
\text { eleva- } \\
\text { tion } \\
\text { without } \\
\text { strain }\end{array}$ & \multicolumn{2}{|c}{$\begin{array}{c}\text { Mean maximum } \\
\text { elevation }\end{array}$} \\
\cline { 3 - 5 } & $\begin{array}{c}\text { Without } \\
\text { strain }\end{array}$ & $\begin{array}{c}\text { With } \\
\text { strain }\end{array}$ \\
$\begin{array}{c}\text { A (low angle) } \\
\text { B (compromise } \\
\text { pivot) }\end{array}$ & $\begin{array}{c}\text { Subjects } \\
26\end{array}$ & $\begin{array}{c}\text { Subjects } \\
8\end{array}$ & $\begin{array}{c}\text { Degrees } \\
57\end{array}$ & $\begin{array}{c}\text { Degrees } \\
68\end{array}$ \\
$\begin{array}{c}\text { C (movable } \\
\text { pivot) }\end{array}$ & 100 & 55 & 75 & 87 \\
\hline
\end{tabular}

Teddington, where the pivot of the low-angle sight was determined. Cinematograph films were taken, from a fixed position, of a number of seated subjects simulating the act of sighting from maximum depression to maximum elevation. The films were then projected, frame by frame, at a standard magnification, and the track of the eyes traced on to

squared paper. The mean track of the eyes was determined by superimposing the tracings so obtained. The curve obtained by this method did not correspond with that taken by the binoculars in the case of the low-angle sight (Sight A-see Table). The track of the eyes is, in fact, found to describe two major curves with different centres. The first curve, which is described by the eyes from $20^{\circ}$ depression to about $40^{\circ}$ elevation, is centred in the region of the atlanto-occipital joint, and corresponds to a combination of head and neck movements; and the second, of longer radius, is described by the eyes above $40^{\circ}$ elevation and is due chiefly to movements of the trunk (fig. 4). The oculars can be made to travel approximately along the track of the eyes by pivoting the sight at the centre of the mean of the two curves mentioned above, or more accurately, if a movable pivot is incorporated by operating through a cam mechanism so that the binocular eye-pieces actually follow the mean track of the eyes described from $20^{\circ}$ depression to zenith. (figs. $5 a$ and $b$ ). When the first method, using the compromise pivot, was put to a practical 
test, it was found that a considerable improvement had been effected but that the low position of the pivotal point had certain mechanical disadvantages (Sight B, see Table). The second method, incorporating a movable pivot (Sight $C$, see Table), gave a further improvement in the range of elevation and had the added advantage that some existing low-angle sights could be modified to incorporate such a mechanism with the minimum of interference with the design. In order to determine the relative efficiencies of sights with pivotal points in different positions, the maximum elevation in each was determined in 100 unselected subjects of varying body dimensions within the 90 per cent. range. The Table shows the results obtained. The seat height was carefully adjusted for each subject before commencing the experiment. The oculars were fixed at $5 \frac{1}{2}$ inches from the centre of the back-rest.

\section{Summary and Conclusions}

The machines used in modern warfare have become so complex, and their efficiency can be made so high, that the limiting factor in the accuracy of their operation is the man behind them. For this reason the human factors in engineering design have assumed great importance. Illustrations of the application of anatomical principles to the design of seats and sights for use by the Royal Navy have been given. It is clear that many of the anatomical problems of war are also those of peace, and that there is a large anatomical field yet to be explored.

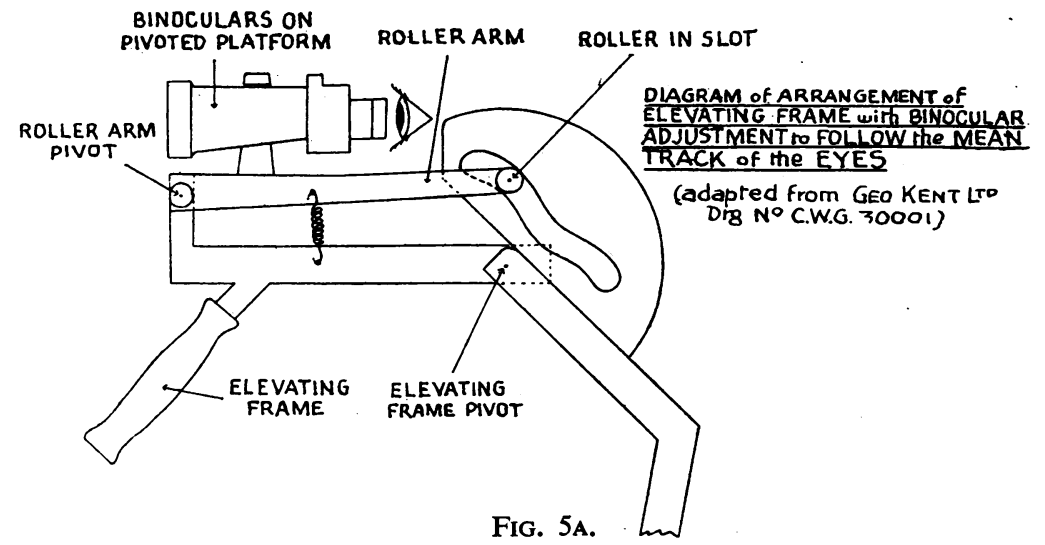

FIG. 5A.

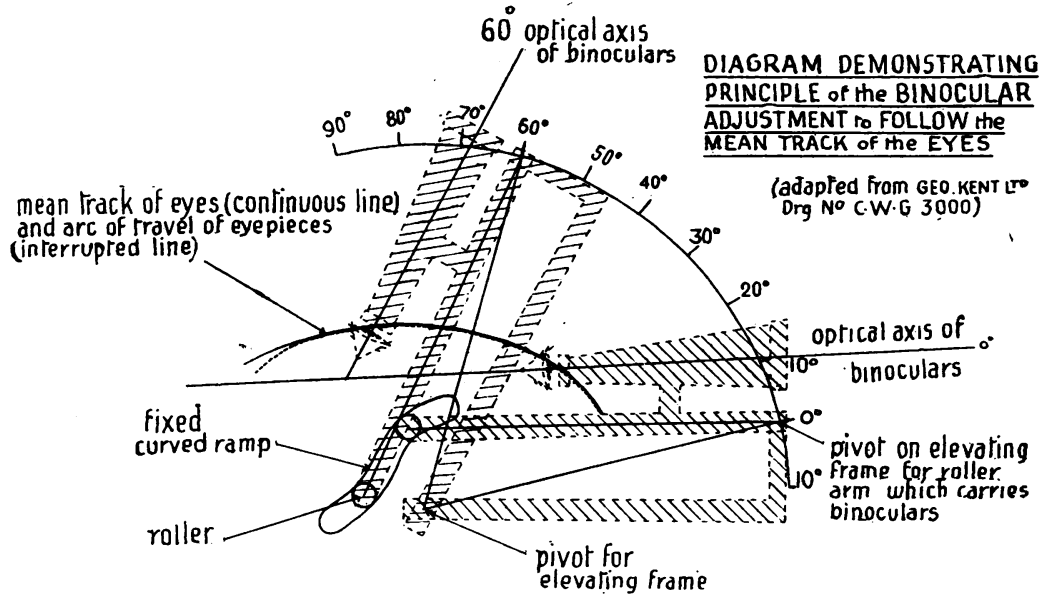

FIG. 5B.

We would like to express our thanks to the Royal Naval Personnel Research Committee of the Medical Research Council, under whose auspices work was carried out, and to the Medical Research Council for personal and equipment grants. We would also particularly like to thank Prof. W. E. Le Gros Clark, Dr. G. L. Brown, Lt.-Cmdr. C. E. J. Streatfield of the Experimental Department, H. M. S. Excellent, and Cmdr. E. J. Golby of the Admiralty Gunnery Establishment, for their personal aid and encouragement.

\section{REFERENCES}

Edwards, F. A., and Duntley, S. Q. (1939). Amer. J. Anat., 65, 1. Haxton, H. (1945). Anat. Rec., 93, 279. 